\title{
GESTÃO DE EMPRESAS NA ECONOMIA DE COMUNHÃO: ESTUDO DE CASO NO NORDESTE DO BRASIL
}

\section{THE MANAGEMENT IN THE ECONOMY OF COMMUNION: A CASE STUDY IN BRAZIL'S NORTHEAST}

\author{
Miguel Otávio Barreto Campelo de Melo ${ }^{1}$; Guilherme Albuquerque Cavalcanti ${ }^{2}$ \\ Alexandre Santos ${ }^{3}$; José Raimundo Vergolino ${ }^{4}$ \\ ${ }^{1}$ Universidade Federal da Paraíba-UFPB-João Pessoa-Brasil - mobcmelo@ct.ufpb.br \\ ${ }^{2}$ Universidade Federal da Paraíba-UFPB-João Pessoa-Brasil - direcao@ct.ufpb.br \\ ${ }^{3}$ Universidade Federal de Pernambuco-UFPE-Recife-Brasil - alexandresanttos@,uol.com.br \\ ${ }^{4}$ Universidade Federal de Pernambuco-UFPE-Recife-Brasil - jose.vergolino@globo.com
}

\begin{abstract}
Resumo
A Economia de Comunhão (EdC) consiste em direcionar a gestão das empresas a se constituírem como uma comunidade voltada à produção de bens e serviços tendo em vista uma sociedade mais solidária na direção de tornar o modelo de racionalidade e utilitarista econômico mais equilibrado. São apresentadas considerações gerais sobre a gestão das empresas com o foco voltado para a Economia de Comunhão (EdC) analisando os seus fundamentos, características $e$ estruturas básicas. A fim de analisar este tipo de gestão foi realizada uma pesquisa com algumas empresas localizadas no Estado de Pernambuco.
\end{abstract}

Palavras-chave: Economia de Comunhão, Gestão, Responsabilidade Social.

\section{Introdução}

O objetivo deste trabalho é apresentar um quadro geral sobre a gestão das empresas com o foco voltado para a Economia de Comunhão (EdC). A estrutura deste artigo contém, além desta introdução tem três seções, onde são abordados os fundamentos da Economia de Comunhão nas empresas e as características e suas estruturas básicas. Na última seção são apresentadas uma pesquisa de campo com algumas empresas que aderiram a EdC.

Os conceitos básicos da proposta de gestão de empresas através da Economia de Comunhão (EdC) surgiram no início da década de 90 em São Paulo pela equipe da Professora Dra Chiara Lubich, fundadora e presidente do Movimento Internacional dos Focolares. A proposta iniciou-se com a criação de um Pólo Industrial tendo como cidade-piloto Mariápolis-Vargem Grande no Estado de São Paulo (BIENER, 2002). 
A Economia de Comunhão (EdC) consiste em direcionar a gestão das empresas a se constituírem como comunidade de pessoas altamente responsáveis e motivadas, voltada à produção de bens e serviços, em vista de uma sociedade solidária e com possibilidades de trabalho. E como se entende serem necessárias pessoas profundamente convictas, há uma motivação em desenvolver as estruturas das "cidadezinhas", chamados de Pólos Industriais de EdC, visando a formação de "homens novos", além naturalmente do incremento à própria empresa (ARAÚJO, 1992).

Vale ressaltar que não se trata de modismo ou de apenas de colocar em comum moeda ou bolsas de auxílio para atingir os fins já mencionados, mas sim de criar empregos, investir os lucros das empresas em projetos de expansão. Também é incluído o fornecimento de equipamentos ou serviços, colocar em comum a experiência adquirida, a gestão e capacidade gerencial, bem como as patentes. A partilha não deve ser apenas de bens materiais, mas também de propósitos, de tempo e de capacidades (QUARTANA apud SERAFIM, 2001). Trata-se, portanto, de uma reviravolta que coloca os talentos, a capacidade e a gestão da produção empresarial a serviço do bem comum. Seus princípios de atuação tomam como base os seguintes objetivos:

a) Ajudar os que se encontra em necessidade, oferecendo-lhes condições de melhoria de vida e possibilidade de emprego;

b) Incrementar a própria empresa;

c) Desenvolver estruturas visando à formação de Homens Novos.

Ressalta-se que esta nova forma de gestão obteve uma expressiva aceitação e repercussão imediata em várias partes do mundo. Atualmente o modelo de organizações que aderiram aos conceitos de Economia de Comunhão (EdC) já conta com mais de 800 empresas de variados portes, localizadas nos cinco continentes: 470 na Europa, 100 no Brasil, 170 nas Américas, quarenta e duas na Ásia, quatro na África e cinco na Austrália (EoC, 2008).

Grande parte dessas empresas se concentram em pólos produtivos ou industriais, um dos elementos básicos que compõem a primeira intuição da $\mathrm{EdC}$, que funcionam como laboratório visível e ponto de referência ideal e operativo também para as outras empresas do projeto.

\section{Características e Estruturas Básicas da EdC}

De acordo com Monteni apud Vido (2004) a Economia de Comunhão (EdC) possui as seguintes características principais:

a) Presença na economia de mercado: As empresas da economia de comunhão não são um grupo isolado, mas estão dentro da realidade do mercado.

b) Atenção tanto à produção quanto à distribuição da riqueza: Diferente de outros movimentos sociais que se voltam apenas para a distribuição da riqueza considerando a maneira de 
agir do sistema econômico como inaceitável, a economia de comunhão valoriza o processo de maneira global, ou seja, desde a produção até a distribuição da riqueza dentro da sociedade.

c) Liberdade de participação: A economia de comunhão se apresenta como uma experiência de liberdade. Nada é imposto. Cada empresário decide aderir de maneira autônoma ao projeto, na medida sugerida pelas circunstâncias da empresa e pela sua situação pessoal e familiar. Os empresários também são livres para formular como serão destinados os lucros entre o crescimento da empresa, o auxílio das pessoas em dificuldades econômicas e a difusão da cultura do partilhar.

d) Compromissos que vão além dos limites da empresa: As pessoas envolvidas no projeto da EdC são movidas por um "ímpeto ideal", a orientação a um compromisso que vai além dos limites da empresa.

No encontro do Bureau Internacional de Economia e Trabalho em 2000, (BARAÚNA,1999), foram definidos os seguintes princípios e valores das empresas da EdC:

-Empresários Trabalhadores e Empresa: Os empresários formulam estratégias, objetivos e planos empresariais, baseados em critérios característicos de uma gestão correta e participativa. Têm como enfoque principal a pessoa humana e não o capital, adotando assim medidas para ajudar os funcionários que passam por dificuldades valorizando seus talentos individuais.

-Relacionamento com Clientes, Fornecedores, Sociedade Civil e com Terceiros: A empresa busca oferecer produtos e serviços de qualidade e a preços justos, ressaltando as características dos mesmos, porém sem depreciar ou ressaltar os defeitos de produtos ou serviços dos seus concorrentes. Os membros da empresa trabalham no sentido de construir e manter boas relações com os clientes, fornecedores, com a comunidade e a administração pública, produzindo um desenvolvimento econômico menos sujeito à variação do mercado e enriquecendo a empresa de um capital "imaterial", baseado em relacionamentos de estima e confiança.

-Ética: A Empresa tem a preocupação com o cumprimento das leis e a manutenção de um comportamento correto perante o governo, os sindicatos, as organizações institucionais e entre todos os membros da empresa. Ela mantém o pagamento de seus impostos em dia e presta a máxima atenção para não poluir, oferecendo assim produtos e serviços com qualidade e respeito aos seus consumidores.

-Qualidade de Vida e da Produção: Além da preocupação com o cumprimento dos requisitos legais relacionados à saúde e segurança dos trabalhadores, os empresários da Economia de Comunhão preocupam-se com a qualidade dos relacionamentos interpessoais dentro da empresa, conscientes de que o esforço para solucionar dificuldades pode resultar em melhores relacionamentos, em estímulos a inovações, incrementando a produtividade, e evitar danos ao meio ambiente, economizando energia e reservas naturais durante o ciclo de produção. 
-Harmonia no Local de Trabalho: O ambiente de trabalho deve ser limpo, organizado e agradável. A empresa adota sistemas de gerência e estruturas organizacionais, visando a promoção tanto do trabalho em grupo como do trabalho individual.

-Formação e Instrução: O empresário deve incentivar a criação de uma atmosfera onde os talentos, idéias e capacidades dos funcionários sejam colocados de uma forma natural, em benefício do crescimento profissional e do progresso da empresa. Deve estabelecer critérios de seleção de funcionários e planos de treinamento e desenvolvimento de pessoal, com recursos do aprendizado.

- Comunicação: A empresa que adere a EdC estabelece uma comunicação aberta e sincera com todos membros da organização. São utilizados meios modernos de comunicação, a fim de manter contatos produtivos em nível local e internacional. Procuram partilhar as alegrias e sucessos e ajudar-se nos momentos de dificuldades, mantendo um espírito de cooperação e solidariedade.

Na Tabela 1 a seguir Gonçalves (2004), apresenta as diferenças dos fundamentos da economia clássica e a de comunhão. Observa-se, portanto, que na Economia de Comunhão (EdC) a solidariedade tem lugar sobre individualismo, homem tem primazia sobre o capital, não havendo oposição entre bem individual e bem social e tendo a cultura de Ser para Si substituída pela do Ser com o Outro.

Tabela 1- Diferenças dos Fundamentos da Economia Clássica e a de Comunhão

\begin{tabular}{|c|c|}
\hline Economia Clássica & \begin{tabular}{|c|} 
Economia de Comunhão \\
\end{tabular} \\
\hline Modo de Produção Capitalista & Modo de produção de Economia de Comunhão \\
\hline $\begin{array}{l}\text { A linha original de continuidade entre a ética e } \\
\text { economia é interrompida }\end{array}$ & $\begin{array}{l}\text { A linha original de continuidade entre a ética e } \\
\text { economia é incluída }\end{array}$ \\
\hline O individualismo na base das relações econômicas & A solidariedade na base das relações econômicas \\
\hline Cultura de ter & Cultura de dar \\
\hline $\begin{array}{l}\text { A racionalidade consiste na utilidade, na } \\
\text { acumulação e em elevar ao máximo o lucro privado }\end{array}$ & $\begin{array}{l}\text { A racionalidade consiste na doação e partilha do lucro } \\
\text { e pressupõe a personalização do relacionamento e a } \\
\text { felicidade humana }\end{array}$ \\
\hline $\begin{array}{l}\text { Homo Economicus, Homo consumerico } \\
\text { individualista, hedonista e egoísta }\end{array}$ & Homo Doador, Solidário, Homo espiritual \\
\hline Oposição entre bem individual e bem social & Não oposição entre bem individual e bem social \\
\hline O capital tem primazia em relação ao homem & O homem tem primazia em relação ao capital \\
\hline $\begin{array}{l}\text { A relacionalidade incorpora sempre o elemento de } \\
\text { condicionalidade }\end{array}$ & $\begin{array}{l}\text { A relacionalidade incorpora sempre o elemento de } \\
\text { gratuidade }\end{array}$ \\
\hline $\begin{array}{l}\text { Prevalência da racionalidade } \\
\text { racionalidade do } \boldsymbol{E} \boldsymbol{U}\end{array}$ & $\begin{array}{l}\text { Prevalência da racionalidade substantiva, da } \\
\text { razoabilidade que segundo Aristóteles contém } \\
\text { elementos de sabedoria. Racionalidade do EU com } \\
\text { Todos }\end{array}$ \\
\hline $\begin{array}{l}\text { Os indivíduos não estão ligados uns aos outros por } \\
\text { nexos indivisíveis antes de iniciar a troca }\end{array}$ & $\begin{array}{l}\text { Os indivíduos estão ligados uns aos outros por nexos } \\
\text { indivisíveis antes de iniciar a troca }\end{array}$ \\
\hline A cultura de Ser para SI & A cultura de Ser com o Outro \\
\hline Apropriação privada do excedente & $\begin{array}{l}\text { Apropriação do excedente privada e partilhada com } \\
\text { dois atores beneficiários fora do processo produtivo }\end{array}$ \\
\hline $\begin{array}{l}\text { Foco na avaliação dos resultados econômicos do } \\
\text { mercado }\end{array}$ & Foco nos atores sociais \\
\hline Esquecimento da premissa antropológica & Afirmação da premissa antropológica \\
\hline Empresa e Sociedade & Empresa na Sociedade \\
\hline
\end{tabular}




\subsection{Bases da Gestão nas Empresas de Economia de Comunhão}

Um dos pontos mais característicos da Economia de Comunhão (EdC) é a chamada Cultura do Partilhar. Segundo esta cultura o ser humano é naturalmente chamado mais para doar do que para ter. Ou seja, se realiza mais doando do que possuindo. A solidariedade só pode existir quando se cala o próprio egoísmo $(\mathrm{LUBICH}, 2002)$. Para a adesão a gestão de empresas através da Economia de Comunhão é convidada empresas despertas aos princípios da solidariedade, bem comum, primazia do trabalho sobre o capital, destinação universal dos bens e dignidade humana, e a responderem a princípios e valores ético-espirituais nos negócios.

Considera-se que a empresa na sociedade humana e ambiental destinam o lucro para três finalidades: Reinvestimento na empresa; Partilha com os excluídos do sistema econômico vigente; Formação de homens e mulheres novos capazes de afirmarem a racionalidade de comunhão (BRUNI, 2002). Este conceito está de acordo com o que Bruni et al. (2008) aborda sobre o conceito que o bem estar do individuo é um dos mais importantes desejos que o homem almeja.

Ferruci (2005) afirma que o projeto de Economia de Comunhão na liberdade é uma verdadeira reviravolta antropológica de caráter não só econômico, mas também cultural. À base da economia dominante está o individualismo, uma das qualidades fundamentais do Homo Economicus. Na Economia de Comunhão, pelo contrário, o modelo do homem econômico é a pessoa em relação de reciprocidade com os outros.

Em seguida na Tabela 2 são apresentados os conceitos e características das empresas capitalistas, as solidárias e as de Economia de Comunhão (EdC).

Tabela 2 - Conceitos e Características das Empresas Capitalistas, Solidárias e de Comunhão

\begin{tabular}{|c|c|c|}
\hline Capitalistas & Solidárias & Economia de Comunhão \\
\hline $\begin{array}{l}\text { A finalidade básica é maximizar o } \\
\text { lucro sem considerar os meios, para } \\
\text { depois ser apropriado pelos } \\
\text { acionistas e proprietários dos meios } \\
\text { de produção }\end{array}$ & $\begin{array}{l}\text { A finalidade } \text { básica não é } \\
\text { maximizar o lucro, mas a } \\
\text { quantidade e a qualidade do } \\
\text { trabalho }\end{array}$ & $\begin{array}{l}\text { A finalidade básica é maximizar o } \\
\text { lucro sem considerar os meios, } \\
\text { para depois partilhar com } \\
\text { beneficiários da EdC }\end{array}$ \\
\hline $\begin{array}{l}\text { A autoridade e o controle } \\
\text { pertencem aos investidores e aos } \\
\text { acionistas }\end{array}$ & $\begin{array}{l}\text { A autoridade e o controle } \\
\text { pertencem aos funcionários }\end{array}$ & $\begin{array}{l}\text { A autoridade } \text { e o controle } \\
\text { pertencem aos empresários, ou aos } \\
\text { empregados } \\
\text { cooperativas }\end{array}$ \\
\hline $\begin{array}{l}\text { Separação entre trabalho e a posse } \\
\text { dos meios de produção é mediada } \\
\text { pela racionalidade instrumental }\end{array}$ & $\begin{array}{l}\text { Não há separação entre trabalho } \\
\text { e a posse dos meios de produção }\end{array}$ & $\begin{array}{l}\text { A separação entre trabalho e a } \\
\text { posse dos meios de produção é } \\
\text { mediada pela racionalidade capaz } \\
\text { de comunhão }\end{array}$ \\
\hline $\begin{array}{l}\text { Tem lucro que é apropriado pelo } \\
\text { capitalista e pelos investidores }\end{array}$ & $\begin{array}{l}\text { Não tem lucro porque nenhuma } \\
\text { parte de sua receita é distribuída } \\
\text { em proporção às cotas de capital }\end{array}$ & $\begin{array}{l}\text { Tem lucro que é apropriado pelo } \\
\text { empresário, pelos beneficiários da } \\
\text { EdC ou reserva quando se trata de } \\
\text { cooperativa }\end{array}$ \\
\hline $\begin{array}{l}\text { O poder de mando está concentrado } \\
\text { nas mãos dos capitalistas }\end{array}$ & $\begin{array}{l}\text { Poder de mando está concentrado } \\
\text { nas mãos dos empregados }\end{array}$ & $\begin{array}{lccr}\text { O poder de } & \text { mando } & \text { está } \\
\text { concentrado nas } & \text { mãos } & \text { dos } \\
\text { empresários ou dos cooperativados }\end{array}$ \\
\hline Isenção de valores religiosos & Isenção de valores religiosos & Inserção de valores religiosos \\
\hline
\end{tabular}
Fonte: Gonçalves (2004). 
De acordo com Serafim (2001), as bases da gestão das empresas de EdC se exprimem em duas opções: As Individuais e das Organizações Produtivas. Nas opções Individuais tem-se:

- Aspiração a uma comunhão com o outro, feito de abertura recíproca, de estima, respeito e de partilha da condição humana

- Estilo de consumo sóbrio e crítico, respeitoso dos recursos comuns da humanidade e da aspiração natural a uma igualdade substancial com os outros homens

- Uso responsável da própria riqueza, a fim de que ela sirva à promoção do bem comum

- Presença ativa em iniciativas econômicas para o bem comum, que gerem empregos e respondam às necessidades não satisfeitas das pessoas e da comunidade

- Partilha das próprias receitas e dos próprios recursos com o próximo que se encontra necessitado, num relacionamento de igual dignidade

Nas opções das Organizações Produtivas:

- Conciliação das exigências de eficiência e de rentabilidade, com o objetivo de tornar a atividade econômica um verdadeiro lugar de encontro de todos os sujeitos envolvidos

- Participação ativa dos trabalhadores na vida da empresa

- Empenho concreto pela melhoria do âmbito social no qual as organizações atuam, não ficando alheias ao bem comum e às necessidades urgentes das pessoas menos favorecidas com as quais entram em contato

- Estabelecimento de relações de abertura recíproca e de confiança entre consumidores, fornecedores, concorrentes, entre a comunidade local e a administração pública, tendo a atenção voltada para o interesse geral

- Vivência na promoção do pleno respeito pela ética e pelo ambiente.

Como a EdC visa resgatar a dignidade do ser humano no âmbito econômico, e dignidade se entende como a capacidade de agir livremente, a economia de comunhão enfatiza que toda ação de partilha se dê de forma absolutamente livre. Assim, a adesão das empresas aos conceitos de Economia de Comunhão (EdC) tem a exigência que seja feita livremente.

A adesão deve ser isenta de toda pressão do mercado, de toda crise de consciência, de todo cálculo de custo/benefício, enfim, de tudo que não possa ser derivada de uma escolha livre que, dentre as alternativas, opte pelo que sua convicção apontou. Desta forma, a adesão à proposta não pode ser imposta ou obrigada, quer por meios coercitivos ou por meios mais subliminares, como os utilizados pelo marketing (ARAÚJO apud SERAFIM, 2001).

Ressalta-se que a Economia de Comunhão (EdC) na liberdade coloca o homem no centro das ações econômicas e organizacionais. Desta forma, têm-se as organizações feitas para o ser humano e não vice-versa, focando uma hierarquia bem definida de valores entre os meios e os fins. Porém não é suficiente que o homem ocupe o centro, se este for individualista. Sendo assim, de 
modo a legitimar a posição de centralidade do ser humano surge o modelo do Homem Novo, sendo esta condição preliminar para o nascimento e funcionamento da proposta (SORGI,1998).

A categoria do Homem Novo leva a uma outra conseqüência como à superação do caráter de polarização ou antagonismo entre funcionários e empresários. Essa concepção implica uma mudança de mentalidade, não é só o empregado que se põe a serviço do empregador, mas o empregador também se coloca a serviço do empregado.

As empresas são vistas, em nível macro, não apenas como instrumentos geradores de emprego e renda, mas também como distribuidores de riqueza por intermédio do lucro. A participação desses não se restringe apenas aos acionistas e empregados, mas é distribuída. $\mathrm{Na}$ Tabela 3 a seguir é apresentado um resumo dos Custos e Benefícios na EdC.

Tabela 3 - Custos e Benefícios da Economia de Comunhão

\begin{tabular}{|c|c|}
\hline Custos & Benefícios \\
\hline 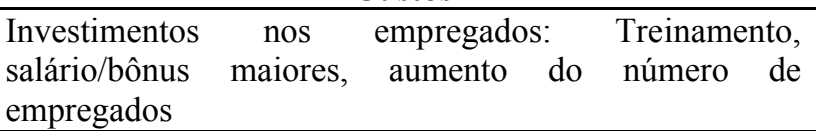 & $\begin{array}{l}\text { Aumento da produtividade com um maior espírito } \\
\text { colaborativo entre os empregados }\end{array}$ \\
\hline Investimento em meio ambiente (tecnologia) & $\begin{array}{l}\text { Níveis maiores de inovação de uma forma natural } \\
\text { em toda a empresa, compartilhando o sentido de } \\
\text { propriedade }\end{array}$ \\
\hline $\begin{array}{l}\text { Investimento em saúde ocupacional e segurança do } \\
\text { trabalho }\end{array}$ & $\begin{array}{l}\text { Dedicação dos trabalhadores em trabalhar para } \\
\text { superar dificuldades }\end{array}$ \\
\hline $\begin{array}{l}\text { Investimento na comunidade local, serviços voluntários } \\
\text { para organizações locais. Comunidade dos Focolares }\end{array}$ & $\begin{array}{l}\text { Lealdade dos clientes. Valorizam o processo de } \\
\text { produção e produto }\end{array}$ \\
\hline $\begin{array}{l}\text { Investimento na sociedade global através da distribuição } \\
\text { dos lucros da EdC }\end{array}$ & $\begin{array}{l}\text { Rede internacional de suporte e contatos através } \\
\text { dos Focolares. Tendências autárquicas e } \\
\text { compartilhamento de tecnologia }\end{array}$ \\
\hline Pagamento de Impostos de acordo com a legislação & $\begin{array}{l}\text { Transparência fiscal que possibilita planejamento } \\
\text { cauteloso em épocas de crise }\end{array}$ \\
\hline Perda de pedidos devido a posição contra a corrupção & $\begin{array}{l}\text { Motivação espiritual para suportar pressão ao } \\
\text { invés de enxergar fracassos no projeto. Crença na } \\
\text { "Providência" }\end{array}$ \\
\hline
\end{tabular}

Fonte: Gold apud Silveira (2004).

Ressalta-se o pioneirismo dos princípios de EdC também na esfera pública fruto da parceria entre o Estado do Ceará e o Movimento chamado Shalom, dentro de um Centro de Estudos de Problemas do Semi-Árido. Neste projeto há a orientação aos trabalhos nas áreas: Trabalho e renda, desenvolvimento humano, infra-estrutura, meio ambiente e tecnologia. Este trabalho iniciou-se com um curso em 2005 de Economia Humana e Reciprocidade buscando contribuir com a vida das pessoas que vivem no semi-árido (LEITE, 2005).

\section{Análise da Pesquisa de Campo}

\subsection{Procedimentos Metodológicos}


A fim de investigar o funcionamento de empresas organizadas segundo os preceitos da Economia de Comunhão e analisar aspectos de gestão empresarial, ética e responsabilidade social realizou-se uma pesquisa de campo em nove empresas. A pesquisa foi realizada na região metropolitana do Recife e abordou diversas áreas de produção industriais e comerciais como: Automação e Eletrônica Industrial, Informática, Consultoria Empresarial, Alimentos, Farmacêutica e Produtos Hospitalares, Segurança Eletrônica Industrial e Comercial, Embalagens, Peças e Serviços de Motos e Pólo Industrial.

Foram coletados dados indicativos da motivação dos empresários, dinâmica empresarial, preocupações sociais e ambientais, nível de satisfação de empregados e clientes, vantagens oferecidas a empregados, nível de relacionamento com empregados e clientes, resultados alcançados e nível de conhecimento do poder público sobre o Projeto da EdC. Foram aplicados entrevistas e questionários a empresários, empregados e clientes das empresas visitadas e, ainda, a autoridades municipais. As abordagens foram através de questões quali-quantitativas e do foram do tipo aberto, possibilitando respostas livres, sem nenhum tipo de orientação prévia. Os sujeitos da pesquisa de campo foram empresários, empregados e clientes das empresas visitadas, envolvendo um conjunto de 24 participantes (SANTOS, 2007).

\subsection{Introdução e Aspectos Gerais}

A Empresa 1 é do setor de serviços e indústria, especializada no desenvolvimento de automação empresarial e construção de painéis e outros equipamentos industriais. Iniciou as suas atividades em 2002 e segundo o seu diretor "respira comunhão desde que nasceu", pois descende de família com destacados serviços na área de atividades em "Economia Solidária", como uma empresa comunitária ainda em 1978, e, portanto, já cultivava a cultura da partilha antes de ingressar na Economia de Comunhão. A empresa participa de várias associações de natureza coletiva, como a Câmara Americana (uma entidade de cooperação internacional) e Programa Nacional das Bases Empresariais (PNBE) e Associação Nacional por uma Economia de Comunhão (ANPEC). Além de integrar o Projeto da EdC, também participa de programas de responsabilidade social, contribuindo com o Movimento Pró-Criança, uma espécie de Pastoral da Criança vinculada a Arquidiocese de Recife em PE.

A Empresa 2 desenvolve sistemas de informática e aderiu ao Projeto Economia de Comunhão em 2004. Atua no ramo de comércio e serviços, comercializando produtos de informática e prestando serviços de desenvolvimento de sistemas, consultoria e de assistência técnica nas áreas de conectividade, automação comercial. Atualmente, a empresa, que emprega quatro pessoas, participa de diversos programas de responsabilidade social, oferecendo auxílio a 
escolas e à Associação de Apoio à Criança e ao Adolescente (AACA). O diretor afirma que, como sempre foi inconformado com a injustiça social viu a "resposta para seus anseios", quando conheceu a proposta da EdC. O empresário acrescenta que a Economia de Comunhão prova não ser apenas uma teoria, pois funciona na prática. Para empresário a EdC ajuda a resolver problemas sociais, ajuda a distribuição de renda e valoriza o ser humano".

A Empresa 3 de consultoria empresarial criada em 1988 que atua principalmente nas áreas contábil, administrativa e econômica. Seu diretor afirma que foi "a possibilidade concreta de fazer algo em benefício dos pobres, envolvendo-os em uma nova mentalidade de fraternidade e reciprocidade, que envolve, também, o empresário", que o levou a aderir ao projeto Economia de Comunhão em 1993, acrescentando que é "a crença na seriedade do Projeto..., que, embora para muitos seja uma utopia, é factível”, que o faz nele permanecer. O site da empresa afirma que a empresa "tem um compromisso firmado com a ética e com a legalidade. É uma empresa que tem uma preocupação social. Por isto, está inserida no projeto Economia de Comunhão, que busca, a partir de uma visão antropológica, colocar a pessoa humana em relevo nos seus relacionamentos interpessoais e institucionais, disponibilizando parte de seus resultados para promoção humana". No entender do empresário da L. Associados Ltda, a EdC “ajuda a inclusão dos mais desfavorecidos, ajuda a combater a violência e a pobreza, ameniza os conflitos sociais (ameniza a luta de classe)".

A Empresa 4 está localizada em Igarassu, no litoral Norte do Estado de Pernambuco, é uma empresa que atua nos setores industrial e comercial com atuação na área da panificação, fabricando e comercializando pães, frios, bolos, salgados, pizzas e outros quitutes. Criada em 1997, em Recife originalmente na área de profissionalização de adolescentes com o apoio de uma ONG Italiana, a empresa migrou de setor econômico, ingressando no ramo da pastelaria e panificação. A empresa aderiu ao projeto da EdC no ano 2000 e, quatro anos mais tarde, transferiu-se para Igarassu, onde funciona até hoje com 12 funcionários. O diretor afirma que decidiu aderir ao projeto porque a Economia de Comunhão "pode salvar as pessoas dos malefícios da Economia de Mercado", "valoriza os bens relacionais, colocando o acima dos bens materiais" e, ainda, que "o bom relacionamento oferece retornos não econômicos e, também, econômicos", acrescentando que confia na proposta porque "a EdC leva as pessoas a pensarem umas nas outras, produzindo uma sociedade mais digna”. Falando sobre os problemas sociais que a EdC ajuda a resolver, o dirigente diz que "a EdC valoriza o homem e, assim, contribui para reduzir os desníveis sociais e a violência" e "dá dignidade às pessoas", resume o empresário. A empresa participa da Associação Comercial de Igarassu, Sindicato da Indústria da Panificação e da Associação Nacional por uma Economia de Comunhão (ANPEC).

A Empresa 5 é uma distribuidora de produtos farmacêuticos e materiais hospitalares foi inaugurada em 2007 e também marcou a inauguração do Pólo Ginetta - um pólo produtivo com 
área total de $83.000 \mathrm{~m} 2$, localizado nas proximidades da Mariápolis Santa Maria em Igarassu, na Região Metropolitana do Recife, contemplando, além de áreas para a administração, serviços e proteção ambiental.

A Empresa 6 iniciou suas atividades em 1998 e atua no ramo de equipamentos de segurança em condomínios sob o slogan "Segurança eletrônica com tecnologia"”. A empresa teve um grande crescimento recente onde houve um incremento de dos 4 funcionários que tinha no início das atividades para 25 atualmente. O diretor é entusiasta da Economia de Comunhão desde o início do Projeto, em 1991 e aderiu ao Projeto da EdC em 2003 e afirma que foi a "convicção de que só faz sentido manter e tocar uma empresa que cultive a cultura da partilha" que o levou a aderir ao projeto Economia de Comunhão e é a "crença e a confiança do Projeto" que o mantém nele. A empresa participa do sindicato patronal do comércio. Para o diretor da empresa, "o maior impacto da EdC, para a solução de problemas sociais, especialmente o de segurança, é a formação de Homens Novos, que, como se fosse uma onda, impulsiona a cultura da partilha no tecido social".

A Empresa 7 aderiu ao Projeto Economia de Comunhão em 1992, e foi uma das primeiras empresas da EdC em Pernambuco, atua tradicionalmente no comércio de sacos para embalagens, tendo no setor açucareiro o principal cliente, e, mais recentemente, no comércio de material da linha de cama, mesa e banho. Possui no conjunto, 52 funcionários e é filiada à Associação Nacional por uma Economia de Comunhão (ANPEC). O diretor afirma que as palavras contrastando a "cultura do ter" vigente no mundo atual com a "cultura do doar", o levaram a inserir a empresa no Projeto da EdC. "Nós temos que comungar nossas coisas com os mais necessitados, pois o sentido maior da empresa não é ganhar dinheiro, mas servir ao próximo, tratar bem as pessoas, os funcionários, clientes, até por formação religiosa... tratar bem e honestamente", diz o empresário, acrescentando que "quando a pessoa trata bem as pessoas é recompensado por isso".

A Empresa 8 atua no comércio de peças e acessórios para motocicletas possui quatro funcionários, aderiu ao Projeto Economia de Comunhão desde sua fundação em 1998 e também participa da Associação Nacional por uma Economia de Comunhão (ANPEC).

A Empresa 9 é um exemplo dos demais pólos produtivos, que oferecem grande visibilidade à Economia da Comunhão: O Pólo industrial e Comercial Ginetta. Na área ambiental, além de cuidados com o terreno, os projetos dos galpões aproveitam a ventilação natural para reduzir o uso de energia na climatização. O diretor financeiro do Pólo afirma que, ao estimular a cultura da solidariedade, a Economia de Comunhão ajuda a resolver o egoísmo e a falta de amor ao próximo.

\subsection{A Ética, Responsabilidade Social e o Bem Estar Coletivo}


Os empresários que estão à frente das empresas da Economia de Comunhão revelam grande inquietação com a ética, responsabilidade social, colocando o bem comum acima de preocupações eminentemente financeiras, quesito que, por si só, indica a importância destas empresas para o sucesso de certos projetos que contribuem para o desenvolvimento local.

Comentando sobre a decisão de incluir a Empresa 1 no Projeto EdC seu diretor se refere a "busca por justiça social” e a "possibilidade de colocar em prática a Doutrina Social da Igreja Católica". Afirma que a EdC ajuda a resolver o desemprego, a desumanização do ambiente de trabalho e a má distribuição de renda, destacando que "a principal mudança cultural ocorre dentro da empresa e isto diz respeito, também, a distribuição da renda..., pois o lucro não é justo se não houver partilha". Segundo o seu diretor, "o lucro não é justo se não houver partilha”, o relacionamento com os empregados decorre "da melhor qualidade possível, com amizade, como colegas que se querem bem", no que é confirmando pelo funcionário eletrotécnico, coordenador de obra. O empregado afirma que trabalhar empresa, onde está há um ano e meio, "é ótimo, pois a empresa tem uma filosofia de respeito às pessoas, que permite a participação". Para representar seu nível de satisfação, diz que ao tempo que, numa escala de 0 a 10, daria 4,5 às empresas em que já trabalhou anteriormente, e daria 9,0 a empresa atual. O seu diretor conclui que "a Economia de Comunhão estimula a cooperação e a solidariedade entre as pessoas". Na empresa um dos seus empregados afirma que há uma preocupação com a felicidade dos funcionários e leva em consideração a qualidade profisssional em "comportamento atípico em relação ao mercado". Ressalta que este tipo de empresa "contribui, e contribui muito, para a melhoria das condições de vida do ambiente em que atua". Entusiasmado com a empresa em que trabalha, diz que a contribuição das empresas da EdC extrapola o ambiente em que atuam, contribuindo "para a melhoria do país, com a mudança das famílias, dos país, dos filhos, das esposas, etc...”.

Quanto ao relacionamento com os clientes o diretor da Empresa 1, classifica o seu relacionamento "de boa qualidade, com respeito, humana, calorosa, sem conflitos". Um dos seus clientes se diz "muito satisfeito", classificando-a como "a nossa melhor parceira". Afirmou que não sabia ser a empresa integrada ao projeto da EdC, diz que percebe diferença entre o modo de proceder da sua fornecedora ou parceira como ele diz, que, no seu entender, "é muito correta, muito ética, além de ser muito competente do ponto de vista técnico". Também afirmou que além da questão comercial, a empresa tem "um comportamento muito sério, ensejando um relacionamento baseado na confiança”. O sócio proprietário empresa 1 acrescenta que, que não estão voltadas para o lucro qualquer custo, as empresas da EdC se comprometem em adotar um comportamento ético, inclusive com o meio ambiente.

Na Empresa 2, onde o seu diretor diz ver os empregados como "parceiros, num clima de respeito mútuo, como se fosse uma família”, a sua funcionária atendente, se diz satisfeita com o 
emprego, atribuindo a nota 8 numa escala de 0 a 10. O seu sócio-diretor classifica o relacionamento com os clientes como 'muito bom', servindo como demonstração de "uma filosofia de vida e de trabalho, marcada pela transparência". Um dos seus clientes regular há 5 anos, se diz tão satisfeito com os serviços e tratamento que recebe que não sabe dizer se há diferença entre o modo de proceder da empresa e suas concorrentes, pois nunca fez negócios com outras empresas e afirma que "as empresas da EdC melhoram o relacionamento entre as pessoas". Sobre os aspectos de preocupação ambiental este ponto, explicando que, por se basear no valor intrínseco das coisas, a mudança cultural proposta pela Economia de Comunhão é anticonsumista e, portanto, estimula a redução do consumo dos bens, ajudando a preservar a natureza. $\mathrm{O}$ empresário da empresa 2 entende que, em conseqüência do respeito ao ser humano inerente a Cultura da Partilha "respeitar o ser humano é também respeitar o meio ambiente", a EdC ajuda a resolver o problema ambiental.

$\mathrm{Na}$ Empresa 3 a diretoria classifica o relacionamento com os empregados 'muito bom'. A funcionária e técnica em contabilidade afirma que gosta muito de trabalhar na empresa, pois, nela, “os empregados têm 'todas as vantagens', sendo tratados com respeito, com confiança e tem a chance de aprender mais". O empresário classifica o relacionamento com os clientes como "muito bom'. Um dos seus clientes que contrata serviços de consultoria nas áreas contábil e de informática à empresa já há 2 anos, se diz "muito satisfeito, pois além do tratamento comercial, há uma relação de "amizade e confiança, como se fosse parceria". Afirma que depois que tomou conhecimento da EdC, percebendo seu objetivo de "melhorar o mundo e a vida das pessoas", passou a ter mais confiança na empresa e acrescenta que "as empresas da EdC contaminam os ambientes com seu modo de ser, tornando melhores as relações".

Na Empresa 4, o seu proprietário classifica o relacionamento com os empregado, clientes e fornecedores como "muito bom, mas precisa melhorar". O seu empregado padeiro e pasteleiro, diz que trabalhar na empresa "é ótimo, pois formamos uma equipe que trabalha em conjunto (...) uns se preocupam com os outros e todos se ajudam mutuamente". No seu entender, entre as vantagens de trabalhar na empresa está a 'transparência' e explica que "todos os dias, logo cedo, em clima de abertura", patrões e empregados tomam café juntos, momento em que todos podem compartilhar suas alegrias e problemas. Sobre a empresa, onde o empresário classifica o relacionamento com os clientes como muito bom, mas precisa melhorar, o funcionário e motorista se diz um cliente fiel, pois, embora tenha se mudado para local distante, permanece adquirindo produtos diariamente há mais de dois anos. Afirma que está muito satisfeito acrescentando que a empresa "oferece muita qualidade, higiene e bom atendimento" e destaca que, nela, o cliente é "tratado pelo nome pela gerente". Sobre o meio ambiente o empresário afirma: "as empresas seguem os sete pontos da EdC, e isso o leva a contribuir com o meio ambiente" 
$\mathrm{Na}$ Empresa 6 seu diretor classifica o relacionamento com os empregados como 'entre regular e bom, mas tem muito a melhorar', o empregado e auxiliar de compras se diz 'muito satisfeito' com o emprego e, numa escala de 0 a 10, daria 9,0 a seu grau de satisfação. Afirmando que a vantagem de trabalhar na empresa é o "espírito de comunhão com colegas e direção", e diz que este tipo de empresa contribui para a melhoria das condições de vida do ambiente em que atua “pelo papel que ela desempenha”. O diretor proprietário classifica o relacionamento com os clientes 'muito bom', lembrando ser esta uma das razões de crescimento, pois “os nossos principais vendedores são os próprios clientes". Um dos seus clientes se diz muito satisfeito com o atendimento recebido da empresa, da qual adquiriu um sistema de segurança eletrônica em função da relação benefício-custo e solução técnica. O cliente acrescentou que, embora a aquisição original tenha sido do tipo 'esporádico', vem fazendo negócios regulares com a empresa, tendo, inclusive, consultado-a sobre a ampliação do sistema. Sobre a sustentabilidade seu diretor da afirma: "a preocupação com o meio ambiente é espontâneo, pois é um efeito colateral da cultura da partilha”.

Na Empresa 7, o seu diretor afirma que "o sentido maior da empresa não é ganhar dinheiro, mas servir ao próximo, tratar bem as pessoas (funcionários, clientes)". A sua operadora de caixa se diz "muito satisfeita" e, numa escala de 0 a 10, daria nota 10 a seu grau de satisfação em trabalhar na empresa, e considera o seu emprego 'o melhor' que já teve, pois “os patrões são amigos e se preocupam com o bem estar dos funcionários". Ressalta que as empresas da Economia de Comunhão contribuem para a melhoria das condições de vida "na medida em que trata os funcionários bem e com respeito", opinando que empregados "ficam satisfeitos e produzem melhor" e acrescentando que "as pessoas bem tratadas, tratam as outras melhor". Seu diretor afirma que "nós temos tratar pessoas bem e honestamente", classificando como 'bom' o relacionamento com os clientes, pois, em suas palavras, "nós devemos tratar bem os clientes por obrigação e por formação, já que sem ele a empresa não vive”. Uma de suas clientes regular há três anos sem perceber diferença em relação às concorrentes, se diz satisfeita com o tratamento que recebe dos funcionários. Afirma que a EdC ajuda a resolver o problema ambiental, pois "ferir a natureza é ferir a própria humanidade". Explica que, além de colocar o lucro em comum, as empresas da EdC seguem regras que incluem o respeito à natureza, "Essas regras são seguidas por todos os empresários da EdC e é assim que o Projeto ajuda a resolver o problema ambiental", afirma o empresário, lembrando que a adesão a Economia de Comunhão é livre e passa por um período de adaptação cultural, a partir do qual as pessoas não necessitam estímulos ou físcalização para que cumpram as regras.

Na empresa 9 o Pólo Empresarial EDC do Nordeste SA, definido por uma jornalista como "uma espécie de condomínio com indústrias que compartilham o ideal de um mundo mais humanitário (...), mantendo uma gestão aberta à participação dos seus funcionários..." e onde o 
diretor financeiro classifica o relacionamento com empregados, clientes e fornecedores é 'muito salutar', a sua funcionária e secretária-executiva se diz 'muito satisfeita' e afirma ser “muito gratificante trabalhar no Pólo Ginettta (...) por ser um trabalho que tem como objetivo diminuir as desigualdades sociais". Diz que o projeto da Economia de Comunhão contribui para a melhoria das condições de vida do ambiente em que atua, "pois ela é orientada pelos rumos do projeto EdC". O diretor financeiro do Pólo afirma que "apesar de desenvolver a economia, a EdC ajuda a resolver o problema ambiental, pois "estimula a classe empresarial a criar uma cultura de preservação do meio ambiente".

\title{
5. Considerações Finais
}

A seguir são descritas algumas considerações finais sobre este trabalho:

$\mathrm{Na}$ base da economia dominante está o individualismo, uma das qualidades fundamentais do Homo Economicus. Na Economia de Comunhão (EdC), o modelo do homem econômico é a pessoa em relação de reciprocidade com os outros, ou seja, é uma verdadeira mudança de caráter não só econômico, mas também cultural.

A sociabilidade nas empresas de Economia de Comunhão (EdC) é aquela disposição das pessoas que nelas trabalham, para com outro, pela qual um se julga ligado ao outro, pela benevolência, pela paz e pela caridade. Cada qual promovendo e mantendo para com seus semelhantes um estado de sociabilidade pacífica, condizente em geral com a índole amorosa e a finalidade da unidade da proposta de EdC (GONÇALVES, 2004).

$\mathrm{Na}$ Economia de Comunhão (EdC) a solidariedade tem lugar sobre individualismo, homem tem primazia sobre o capital, não havendo oposição entre bem individual e bem social e tendo a cultura de Ser para Si substituída pela do Ser com o Outro.

No sistema empresarial há uma incorporação mesmo que tímida, de outro modo tipos de agir vinculados a princípios éticos multidimensionais. Permite-se, dessa forma, se pensar na hipótese de que a adoção de Responsabilidade Social Empresarial e da Economia de Comunhão a processos de Gestão Empresarial revelam experiências concretas que vão na direção de tornar o modelo de racionalidade e utilitarista econômico mais equilibrado (DALABRIDA, 2005).

\begin{abstract}
The aim of this work is to introduce general information about the companies focused on the Economy of Communion (EoC). The Economy of Communion (EoC) consists of leading the administration having in mind a more solidary society in search of turning the rational and utilitarist model into a more economic balanced one. These companies constitute a community of highly responsible and motivated people, focused on the production of goods and services. The main characteristics of management of these companies is having in their mission and strategic planning
\end{abstract}


the basic principles, Ethics, Social Responsibility and other human values. In order to analyze this type of administration, we carried out a data preliminary research with some companies located in Brazil's Northeast.

Key-words: economy of communion, management, social responsibility.

\section{Referências}

ARAÚJO, Vera. Doutrina social da Igreja e Economia de Comunhão. In: QUARTANA, Pino et al. Economia de Comunhão. São Paulo: Cidade Nova, p. 35-56, 1992.

BARAÚNA, Márcia. (Coord.) Economia de Comunhão e Movimento Econômico: desenvolvimento e perspectivas. Vargem Grande Paulista: Cidade Nova, 1999.

BIENER, Hansjoerg. PESC-3: Environmental Education and Education for Socio-Economic Development.: Economy of Communion. available at: http://www.evrel.ewf.uni-erlangen.de/pesc/R2001-EoC.html, (accessed september 2008).

BRUNI, Luigino; COMIM, Flavio; PUGNO, Maurizio, SEN, Amartya, et al. (2008), Capabilities and Happiness. Oxford, UK: Oxford University Press, 2008.

BRUNI, Luigino. (2002) - Rumo a uma Racionalidade Capaz de Comunhão. In: Economia de Comunhão uma Cultura Econômica em Várias Dimensões, Vargem Grande Paulista: Cidade Nova.

EoC, Economy of Communion. disponível em: http://www.edc-online.org, (accesso em: setembro de 2008).

DALLABRIDA, Ivan S. Responsabilidade Social Empresarial (RSE) e Economia de Comunhão (EdC): Racionalidade Empresarial na Construção do Desenvolvimento Sustentável, ETHOS, 2005.

FERRUCI, A. Economy of Communion in Freedom., disponível em: http://www.focolares.org.br/Page2edc.htm, (accesso em setembro de 2008).

GONÇALVES, H.H. Sociabilidade do Projeto de Economia de Comunhão na Liberdade (EdC), COPPE/UFRJ. In: Engenharia e Desenvolvimento Social, Rio de Janeiro, 2004.

LEITE, Kelen C. Economia de Comunhão: Uma mudança Cultural e Política na Construção do Princípio da Reciprocidade nas Relações Econômicas, Dissertação de Pós-Graduação, UFSCar, 2005.

LUBICH, Chiara. Os Problemas de Desenvolvimento das Empresas de "Motivação Ideal". In: BRUNI, Luigino (Org.); ARAÚJO, Vera; FERRUCCI, Alberto; BURCKART, Hans; GUI, Benedetto; ZAMAGNI, Stefano. Economia de Comunhão: Uma Cultura em Várias Dimensões. Vargem Grande Paulista: Cidade Nova, 2002.

SANTOS, Alexandre F. Uma Abordagem da Economia de Comunhão como Estratégia para o Desenvolvimento Local: o caso das empresas instaladas na região metropolitana do Recife. Dissertação de Mestrado em Gestão Púublica para o Desenvolvimento do Nordeste, Recife, Pernambuco, 2007.

SERAFIM, M.C. A Ética no Espaço de Produção: Contribuições da Economia de Comunhão, Dissertação de Mestrado em Engenharia de Produção, Universidade Federal de Santa Catarina, 2001.

SILVEIRA, N.C. Relações entre Responsabilidade Social e Economia de Comunhão: Um Estudo de Caso com Empresas do Pólo Empresarial Spartaco, USP, Ribeirão Preto, São Paulo, 2004.

SORGI, Tommaso. A Cultura do Dar. In: Economia de Comunhão: Projeto, reflexões e propostas para cultura de partilha. São Paulo: Editora Cidade Nova, 1998.

VIDO, E. Gestão Baseada nos Princípios da Economia de Comunhão: Uma Proposta de Mudança da Cultura Empresarial, Monografia, Universidade Presbiteriana Mackenzie-SP, 2004. 


\section{Autores:}

Miguel Otávio Barreto Campelo de Melo

Universidade Federal da Paraíba (UFPB)

Engenharia de Produção

Cidade Universitária, João Pessoa - PB CEP 58051-970

Telefone: (83) 32167810

e-mail:mobcmelo@ct.ufpb.br

Guilherme Albuquerque Cavalcanti

Universidade Federal da Paraíba (UFPB)

Engenharia de Produção

Cidade Universitária, João Pessoa - PB CEP 58051-970

Telefone: (83) 32167810

e-mail:direcao@ccsa.ufpb.br

José Raimundo Vergolino

Universidade Federal de Pernambuco (UFPE)

Mestrado em Gestão Pública para o Desenvolvimento do NE

Av. dos reitores - s/n. - Cidade universitária

Recife - PE CEP:50670-901

Telefone: (81) 2126-7076 / 2126-7075

e-mail: jose.vergolino@globo.com

\section{Alexandre Santos}

Universidade Federal de Pernambuco (UFPE)

Mestrado em Gestão Pública para o Desenvolvimento do NE

Av. dos reitores - s/n. - Cidade universitária CEP:50670-901.

Recife - PE CEP:50670-901

Telefone: (81) 2126-7076 / 2126-7075

e-mail: alexandresanttos@uol.com.br 